Supporting Information

\title{
Oxygen Reduction Reaction Catalyzed by Black Phosphorus-Supported Metal Nanoparticles: Impacts of Interfacial Charge Transfer
}

Yi Peng, ${ }^{\dagger}$ Bingzhang Lu, ${ }^{\dagger}$ Nan Wang, ${ }^{\S}$ Jia En Lu, ${ }^{\dagger}$ Chunhong Li, ${ }^{\dagger}, \not, *$ Yuan Ping, ${ }^{\dagger}$ and Shaowei Chen $^{\dagger, *}$

${ }^{\dagger}$ Department of Chemistry and Biochemistry, University of California, 1156 High Street, Santa Cruz, CA, 95060, USA

Beijing National Laboratory for Condensed Matter Physics, Institute of Physics, Chinese Academy of Sciences, Beijing 100190, China

$\S$ New Energy Research Institute, School of Environment and Energy, South China University of Technology, Guangzhou Higher Education Mega Centre, Guangzhou, 510006, China

Corresponding Authors

*C. H. Li (chunhongli@iphy.ac.cn),

*S. W. Chen (shaowei@ucsc.edu) 


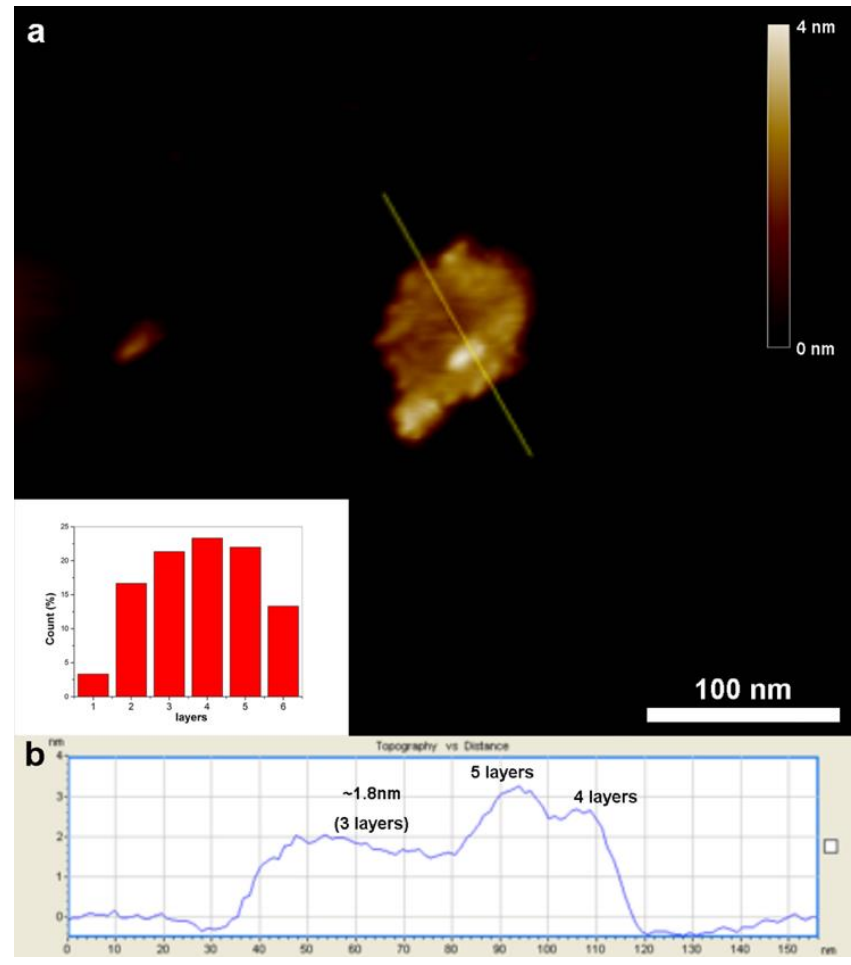

Figure S1. (a) Representative AFM topograph of a TLBP. (b) Height profile of the line scan in panel (a). Note that a single BP layer is ca. $0.6 \mathrm{~nm}$ in thickness. ${ }^{1}$ Thus, the heights of ca. $1.8 \mathrm{~nm}, 2.5 \mathrm{~nm}$ and $3.1 \mathrm{~nm}$ observed in panel (b) correspond to 3, 4 and 5 layers of BP, respectively. Inset to panel (a) is the histogram of the number of BP layers in TLBP, based on statistical analysis of about 50 TLBPs.

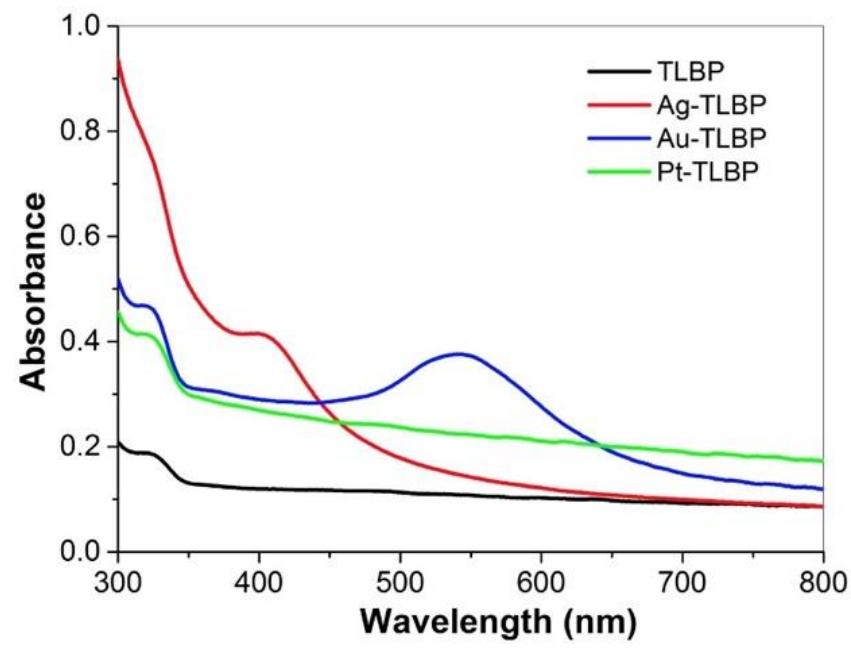

Figure S2. UV-vis spectra of TLBP and M-TLBP $(M=P t, A g$, and $A u)$ in NMP. 


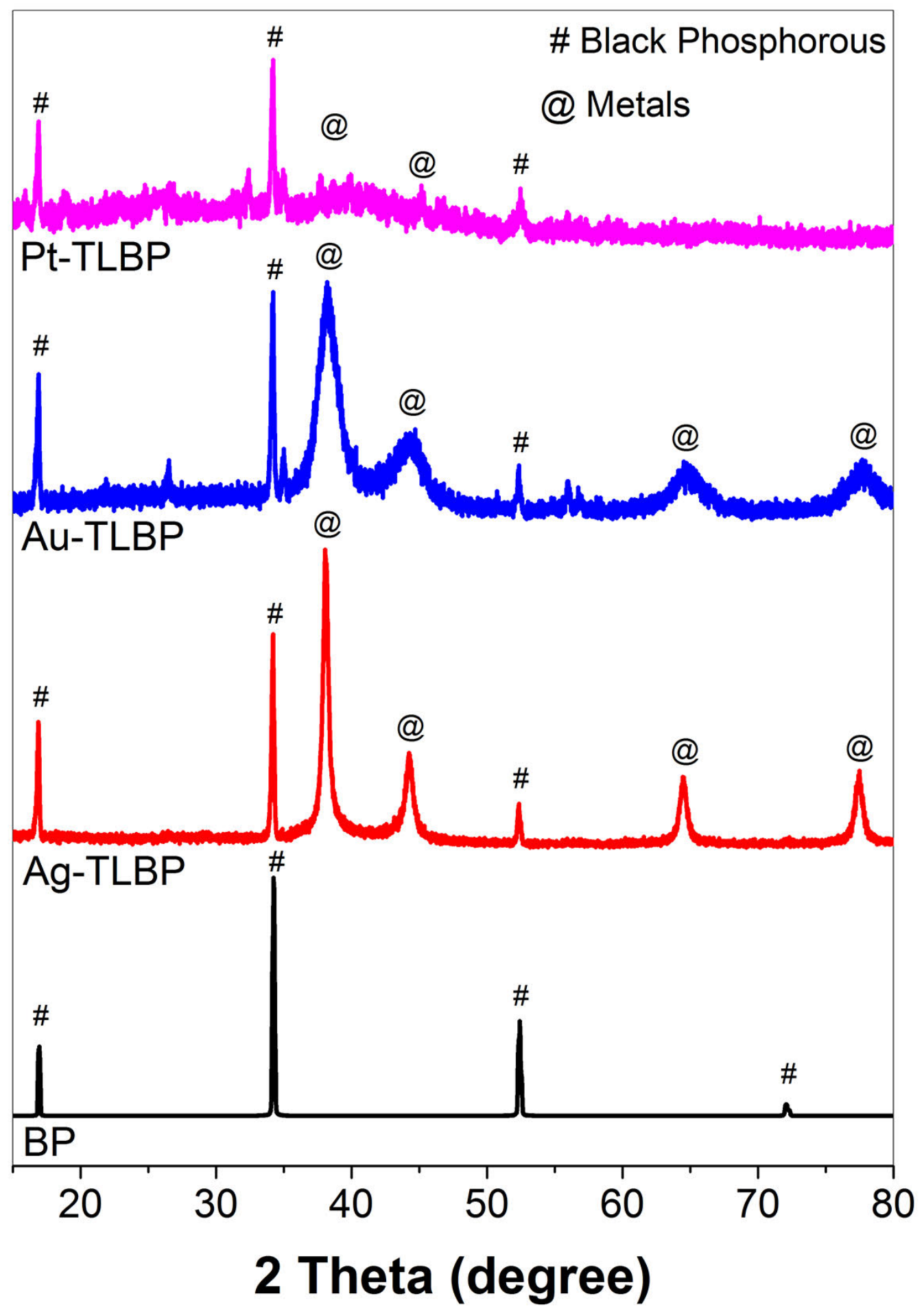

Figure S3. XRD patterns of $B P$ and $M-T L B P(M=P t, A g$, and $A u)$. 


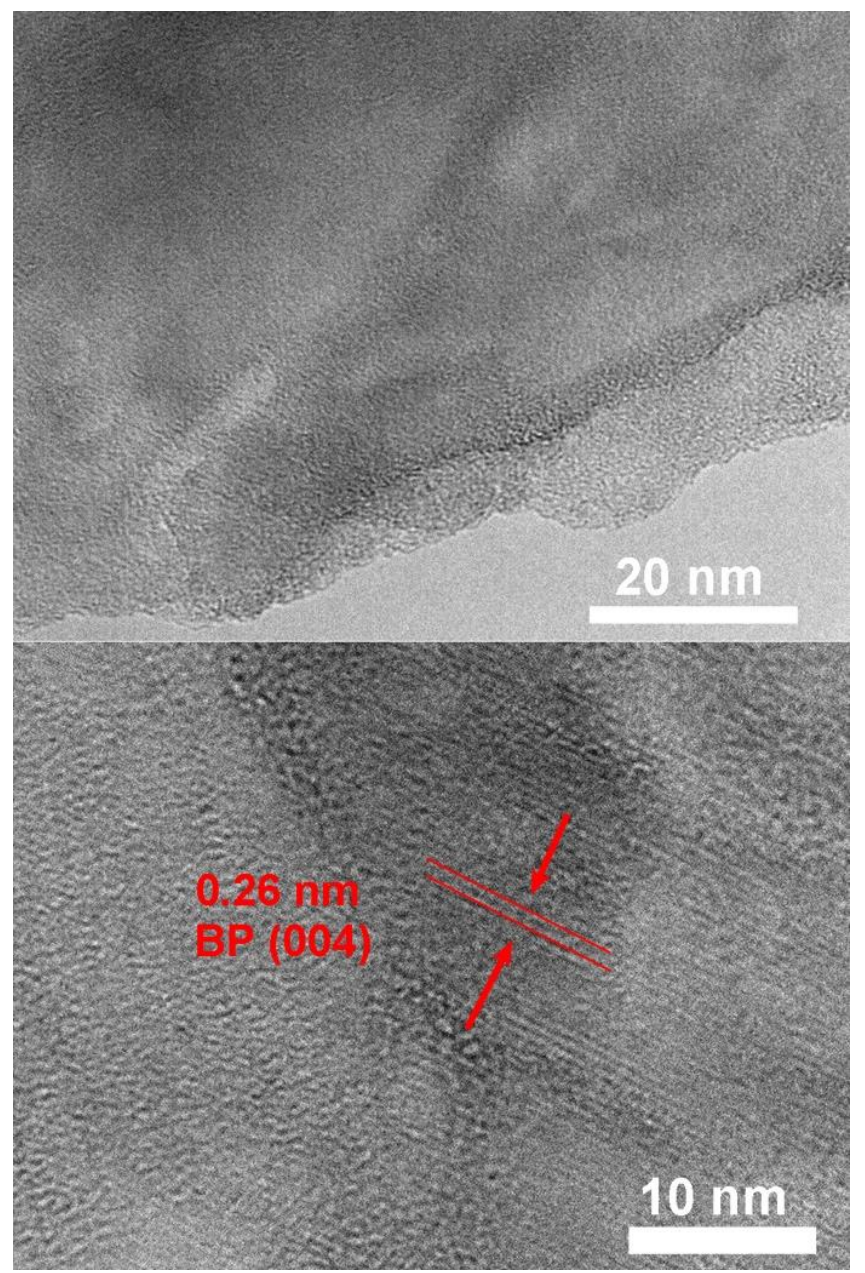

Figure S4. Representative TEM images of TLBP. Scale bars are $20 \mathrm{~nm}$ (top) and $10 \mathrm{~nm}$ (bottom). The interplanar spacing of $0.26 \mathrm{~nm}$ is consistent with the crystalline planes of $\mathrm{BP}(004)$. 

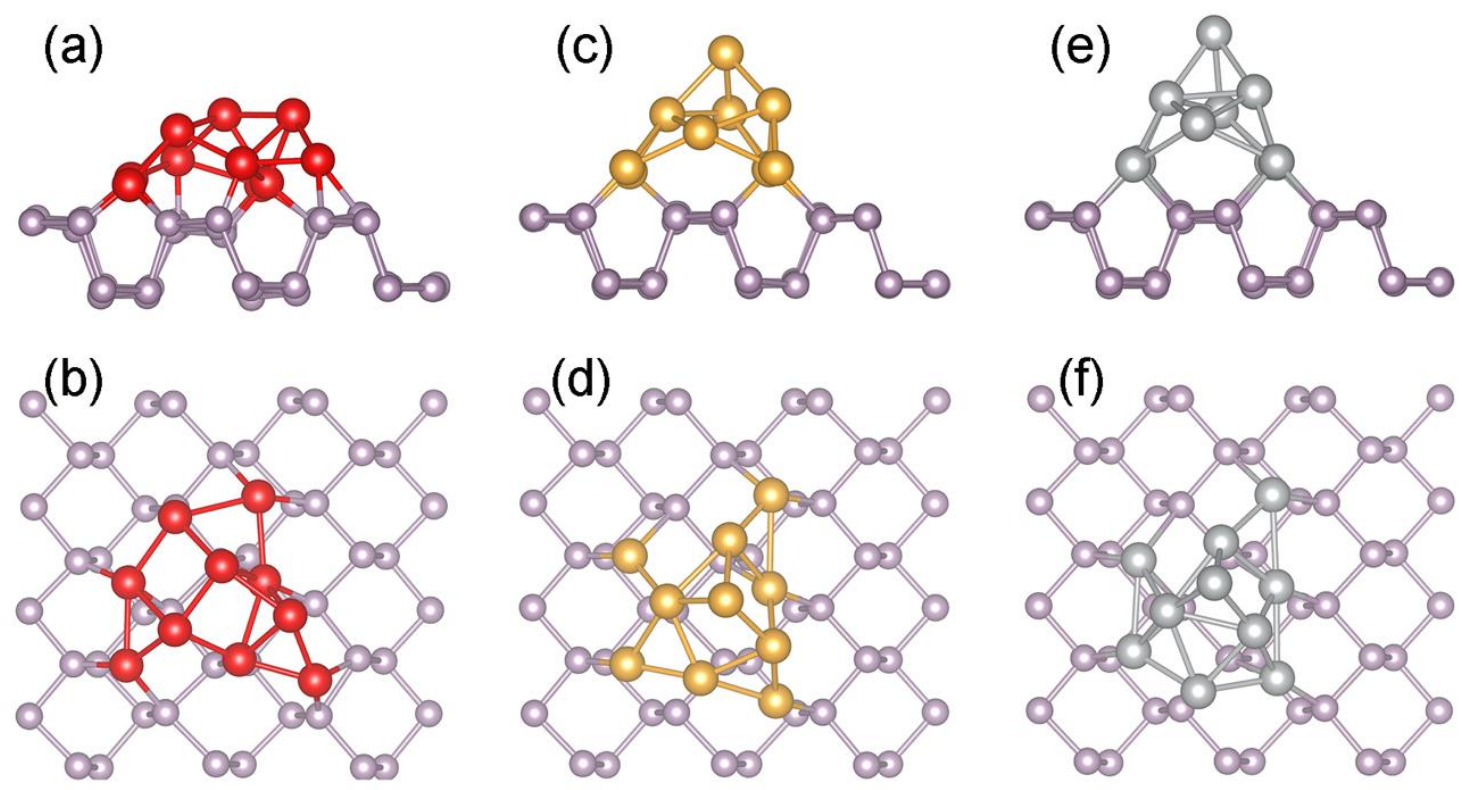

Figure S5. Structural models of M-BP for DFT calculations: (top) front view, and (bottom) top view. (a-b), Pt-BP; (c-d), Au-BP; (e-f), Ag-BP. 

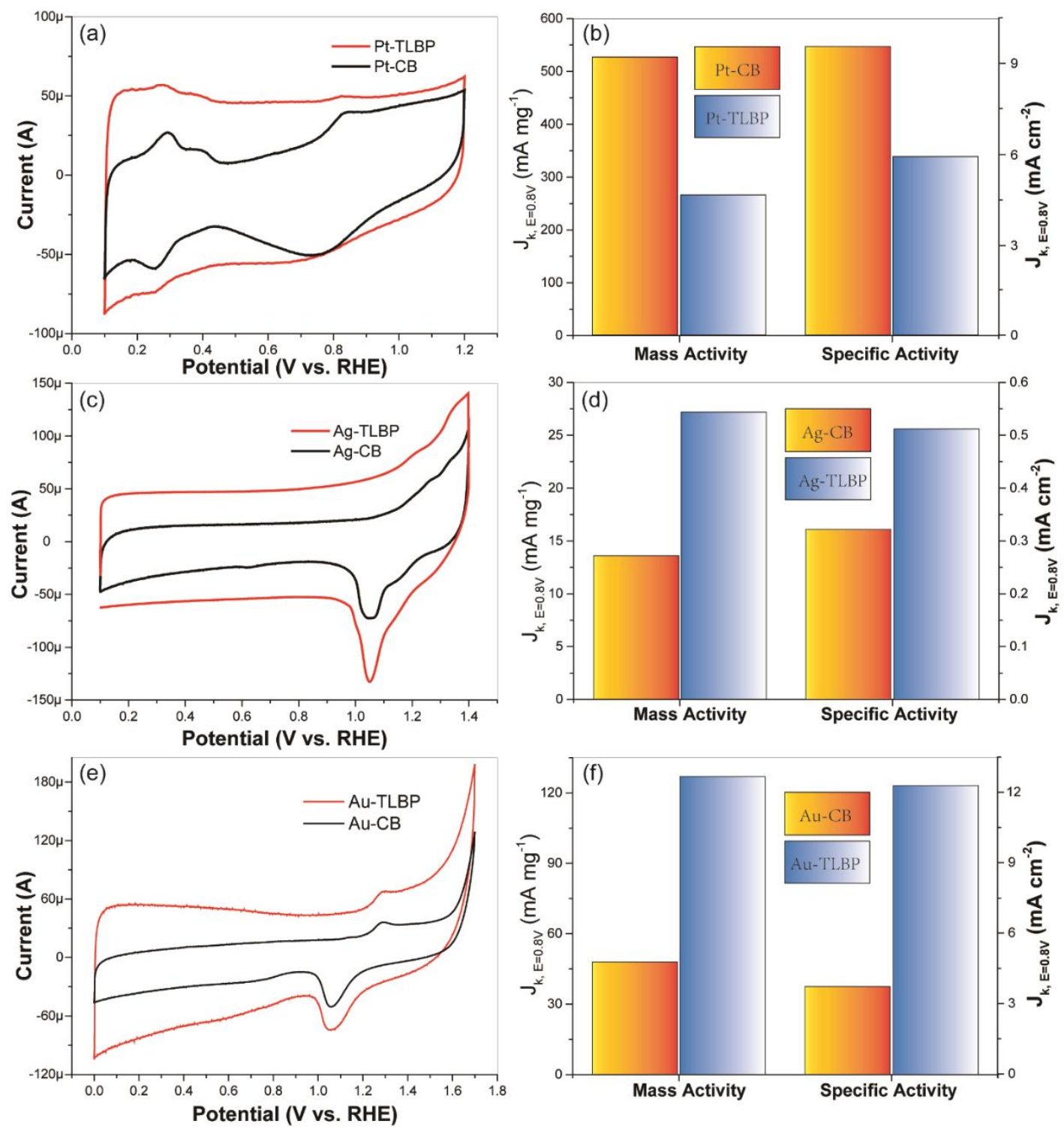

Figure S6. $C V$ curves of M-TLBP and M-CB in $\mathrm{N}_{2}$-saturated $0.1 \mathrm{M} \mathrm{KOH}$ : (a) $M=P t$, (c) $M=A g$, and (e) $M$ $=\mathrm{Au}$. Comparison of the mass activity and specific activity at the potential of $+0.8 \mathrm{~V}$ between M-TLBP (blue bars) and $\mathrm{M}-\mathrm{CB}$ (orange bars): (b) $\mathrm{M}=\mathrm{Pt}$, (d) $\mathrm{M}=\mathrm{Ag}$, and (f) $\mathrm{M}=\mathrm{Au}$.

Prior to ORR measurements, the electrochemical surface area (ECSA) of the catalysts was estimated by collecting the voltammograms in $\mathrm{N}_{2}$-saturated $0.1 \mathrm{M} \mathrm{KOH}$, as depicted in Figure S5. For Pt, the ECSA was calculated by the hydrogen adsorption/desorption within the potential range of 0.1 to $0.45 \mathrm{~V}$. For $\mathrm{Ag}$ or $\mathrm{Au}$, the ECSA was estimated by the silver/gold oxide reduction peak centered at ca. $1.05 \mathrm{~V}^{2-4}$ The corresponding ECSA was calculated to be $55.0 \mathrm{~cm}^{2} / \mathrm{mg}$ for Pt-CB, $45.0 \mathrm{~cm}^{2} / \mathrm{mg}$ for Pt-TLBP, $42.4 \mathrm{~cm}^{2} / \mathrm{mg}$ for Ag-CB, $53.0 \mathrm{~cm}^{2} / \mathrm{mg}$ for Ag-TLBP, $10.4 \mathrm{~cm}^{2} / \mathrm{mg}$ for $\mathrm{Au}-\mathrm{CB}$, and $12.8 \mathrm{~cm}^{2} / \mathrm{mg}$ for Au-TLBP.

The RRDE voltammograms were collected in an $\mathrm{O}_{2}$-saturated $0.1 \mathrm{M} \mathrm{KOH}$ electrolyte at the potential scan rate of $10 \mathrm{mV} / \mathrm{s}$ and rotation rate of 400,900, 1600 and $2500 \mathrm{rpm}$. The electron-transfer number (n) and 
hydrogen peroxide yield $\left(\mathrm{H}_{2} \mathrm{O}_{2} \%\right)$ were estimated by the equations, $n=\frac{j_{d}}{j_{d}+\frac{j_{r}}{N}}$, and $H_{2} O_{2} \%=\frac{\frac{j_{r}}{N}}{j_{d}+\frac{j_{r}}{N}}$, where $\mathrm{j}_{\mathrm{d}}, \mathrm{j}_{\mathrm{r}}$ and $\mathrm{N}$ are disk current density, ring current density and collection efficiency (0.4), respectively. Tafel

plots were derived from the RDE plots using the following equation, $j_{k}=\frac{j_{d} j_{l}}{j_{l}-j_{d}}$, where $\mathrm{jk}$, jd and $\mathrm{j}$ are the kinetic current density, disk current density and limited current density, respectively.

\section{References}

1. Luo, Z. C.; Liu, M.; Guo, Z. N.; Jiang, X. F.; Luo, A. P.; Zhao, C. J.; Yu, X. F.; Xu, W. C.; Zhang, H., Microfiber-Based Few-Layer Black Phosphorus Saturable Absorber for Ultra-Fast Fiber Laser. Opt Express 2015, 23, 20030-20039.

2. Wang, Q. Y.; Cui, X. Q.; Guan, W. M.; Zhang, L.; Fan, X. F.; Shi, Z.; Zheng, W. T., Shape-Dependent Catalytic Activity of Oxygen Reduction Reaction (ORR) on Silver Nanodecahedra and Nanocubes. $J$ Power Sources 2014, 269, 152-157.

3. Luo, Z. M.; Yuwen, L. H.; Bao, B. Q.; Tian, J.; Zhu, X. R.; Weng, L. X.; Wang, L. H., One-Pot, LowTemperature Synthesis of Branched Platinum Nanowires/Reduced Graphene Oxide (BPtNW/RGO) Hybrids for Fuel Cells. J Mater Chem 2012, 22, 7791-7796.

4. Kim, J.; Lee, S. W.; Chen, S.; Shao-Horn, Y., Synthesis and Oxygen Reduction Reaction Activity of Atomic and Nanoparticle Gold on Thiol-Functionalized Multiwall Carbon Nanotubes. Electrochem Solid State Lett 2011, 14, B105-B109. 